\title{
An Instrument for Sampling Marine Muds.
}

\author{
By \\ H. B. Moore, B.Sc., \\ and \\ R. G. Neill, B.A., \\ Assistant Naturalists at the Marine Station, Millport.
}

With 5 Figures in the Text.

THIs instrument was designed for taking marine muds for analysis. The requirements were that it should raise a column of mud, from eight to sixteen inches long, and without appreciable disturbance, or contamination with metal. An instrument working on the same principle was used here by Mr. R. Macdonald, and was made in Oslo. The advantages of the present model are that, while small enough to be worked by hand, it is capable of taking larger samples, and from bottoms of very varying consistencies.

Essentially it is a heavy brass body containing a glass tube, the latter being open at both ends when descending, so that the water may stream through it. The sampler falls under its own weight, and drives deeply into the mud, which partially fills the glass tube. A valve at the top closes when the sampler stops, and by this, and by its own friction against the glass, the mud is held in the tube while the sampler is hoisted. The overall length of the machine is 35 inches, the greatest diameter $3 \frac{3}{4}$ inches, and the weight 35 pounds.

Glass tubes of three different diameters are used, to cope with the varying nature and holding capacity of the ground.

The instrument is shown assembled in Fig. 1, while Fig. 2 shows the details of the valve region. Fig. 4 is a horizontal section of the instrument. The main body is a heavy brass tube (Fig. 4, в), closed at the top by a brass plate, in which is a circular aperture; the lower end is open, but has a projecting flange, threaded externally to take a lock-ring. The main tube or body is 9.57 inches long; the plate at the top is 0.38 inches thick, and the body has an overall length of 9.95 inches. The aperture in the top of the plate is one inch in diameter. The walls of the body are 0.79 inches thick, and its external diameter is 3.75 inches.

The sheath (Fig. 4, D) into which the glass tube is loaded is a tube of .075 inch brass, $14 \cdot 8$ inches long, and $2 \cdot 15$ inches in external diameter. 
Five inches from the top is a heavy flange which fits against the bottom of the body. At its lower end the sheath is turned in to the extent of $\cdot 15$ inch, to give protection to the bottom of the glass tube. The sheath is clamped to the body by a brass lock-ring (Fig. 3, c) which screws on to the bottom of the body. The ring and

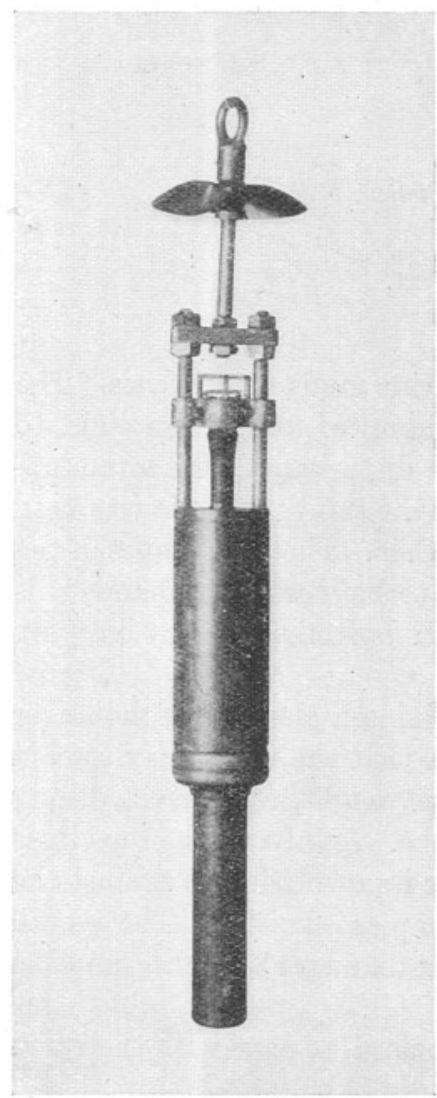

FiG. 1.-Photograph of bottom sampler. sheath are removed when inserting or withdrawing the glass tube.

Two brass rods (Fig. 4, A), 7.45 inches long and 0.63 inches in diameter, rise from the top of the body and support the valve mechanism, which is described below ; to the link which unites them at the top is attached the central rod that bears the propeller. This shaft is 8.4 inches long, and carries at the top a ring for the attachment of a rope. The propeller itself revolves freely on the shaft, and is fitted to ensure straight descent. It has four blades, with a distance from tip to tip of six inches.

The glass tubes and their rubber connections are not shown in Fig. 4. For the sake of clearness, they have been displaced to the right, and are shown as Fig. 5. The shaded areas represent rubber, the unshaded glass. The glass sampler tube is 1.85 inches in external diameter, $0 \cdot 1$ inches thick, and 18.25 inches long: it lies within the sheath, and extends almost to the top of the body. The dimensions of these tubes vary slightly owing to the difficulty of obtaining uniform supplies. The bottom of the glass tube is open; the top receives a rubber bung, which must be tight-fitting. This is pierced for a small glass tube, 3.5 inches long, and just under an inch in external diameter, which passes through the aperture in the top plate of the body, and is connected by a rubber sleeve with the actual valve. The rubber bung, in addition to making the joint, serves to take up some of the shock, if, as sometimes happens, the sampler strikes a stone on the bottom. For the same reason it has been found desirable to adjust the bung so that the larger glass tube is not actually in contact with the turned-in bottom of the sheath. The glass tube is 
held as rigidly as is necessary, when the bung is sufficiently tight-fitting to ensure the essential water-tight joint.

The valve is a glass tube, $2 \cdot 25$ inches long and slightly less than one inch in external diameter. Near the bottom it has a swelling to allow the

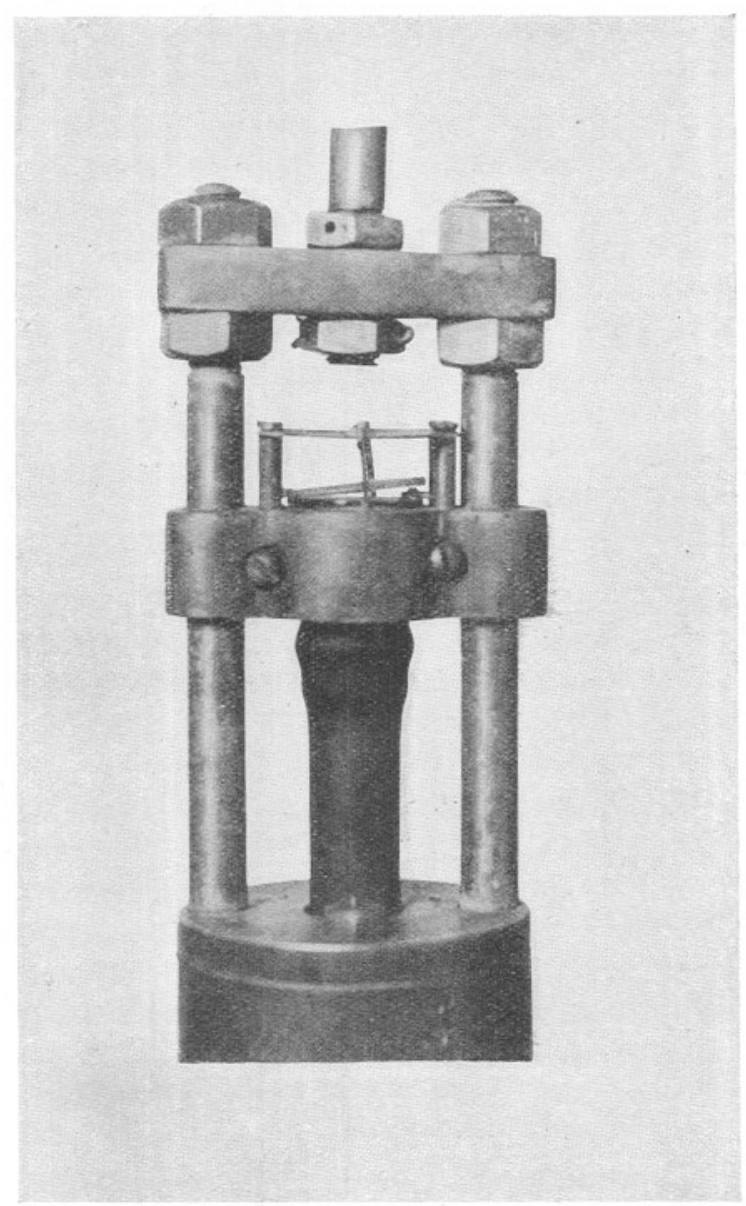

Fig. 2.-Photograph of valve region of bottom sampler.

sleeve to grip it. At the top it is turned over to form a rim about a quarter of an inch wide, and the upper surface of this rim is ground. On it lies a circular ground glass plate, confined only by the small cage shown in the figures. As the sampler descends, the water streams through the tube, and escapes through the valve, the ground glass plate being lifted by the pressure of the water. But as soon as the sampler comes to rest in the 


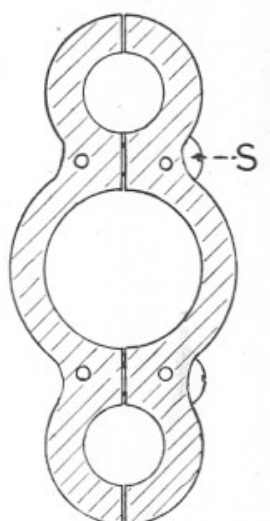

Frg. 3.-Plan of valve bar, $\times \frac{1}{2}$.

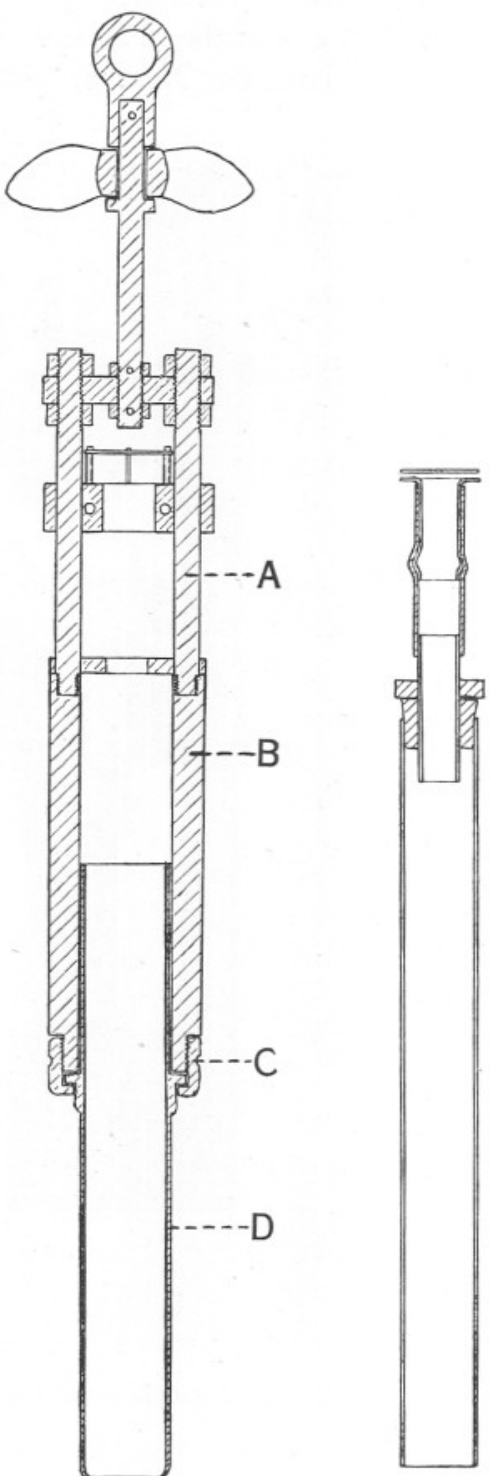

FIG. 4.-Diagram of bottom sampler, $\times \frac{1}{6}$ : for lettering see text.
FiG. 5.-Glass parts of bottom sampler. 
egg case with the egg enclosed, suggest that once the egg has reached the oviduct, events move rapidly.

It is a familiar fact that two ova are shed from the ovaries simultaneously, so that in each oviduct there is an egg in the same stage of development. In the specimen here described it may be noted that both eggs appear to have been shed from the right ovary. In Fig. 1 it can be seen that in the left ovary are several eggs in an advanced stage of development, whereas in the right ovary the largest eggs present are only about halfgrown. This may indicate an alternation in the activity of the ovaries. Many further observations would be needed to establish this, but if it should prove to be generally true, it may readily be seen how, from such a condition, that found in Scyllium canicula, for example, could be derived, in which only one ovary develops and becomes functional.

One further point is illustrated in Fig. 1. In textbooks the oviducal funnels of both the skate and the dogfish are described and figured as being united to form a single median ostium. In Raia radiata, at any rate, this seems not to be the case. The upper and lower lips of the funnels are, indeed, united, but the openings remain so widely separated as to be, probably, functionally distinct. Redeke (1898) stated that in Trygon pastinaca there are two separate ostia (quoted by Ihle, 1927, p. 745). Raia radiata, therefore, seems to exhibit a condition intermediate between this and the completely fused ostia of Raia batis.

\section{REFERENCES.}

Beard, J. On the development of the common skate. Fisheries, Scotland, 8th Annual Report, Pt. III, 1890.

Borcea, I. Sur la glande nidamentaire de l'oviducte des Élasmobranches. C. R. Acad. Sci., Paris, Vol. 138, p. 99, 1904.

Gerbe, Z. Recherches sur la segmentation de la cicatricule et la formation des produits adventifs de l'oeuf des Plagiostomes et particulièrement des Raies. Journ. de l'Anat. et de la Physiol., Vol. 8, p. 609, 1872.

Ihle, J. W. E. Vergleichende Anatomie der Wirbeltiere. Berlin, 1927.

Lamont, A. Relative frequency of species and sex-ratios in the skates and rays (genus Raia). Proc. Roy. Physical Soc., Edinburgh, Vol. 21, 1926.

Perravex, E. Sur la formation de la coque des œufs du Scyllium canicula et du Scyllium catulus. C. R. Acad. Sci., Paris, Vol. 99, p. $1080,1884$.

Sedawick, A. A student's textbook of zoology. Vol. II, London, 1905.

Widakowich, V. Ueber Bau und Funktion des Nidamentalorgans von Scyllium canicula. Zejtschr. wiss. Zool., Vol. 80, p. 1, 1906. 
